Bellón Climent, Antonio. Las actividades económicas en El Palmar (Valencia): entre la tradición y la modernidad. GeoGraphos. [En línea]. Alicante: Grupo Interdisciplinario de Estudios Críticos y de América Latina (GIECRYAL) de la Universidad de Alicante, 21 de febrero de 2014, vol. 5, no 64, p. 206232 [ISSN: 2173-1276]. [DOI: 10.14198/GEOGRA2014.5.64].

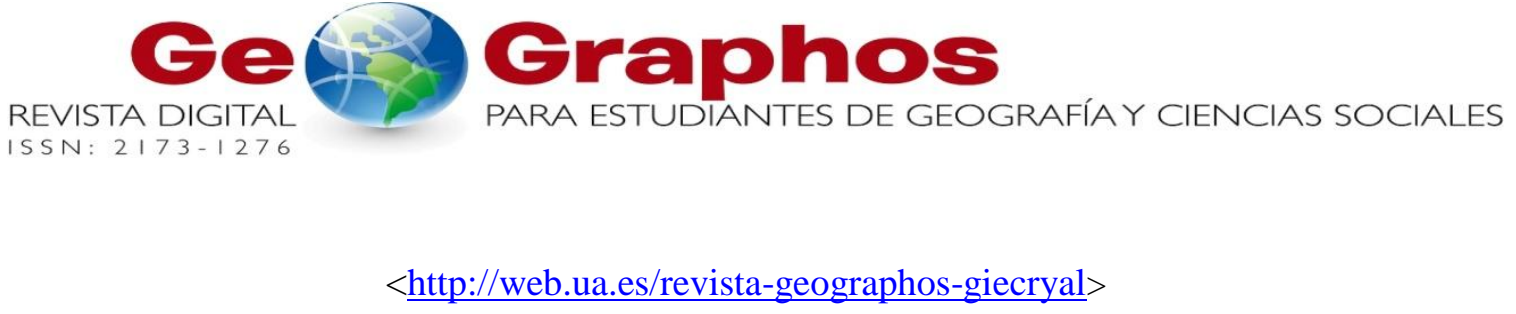

Vol. 5. $\mathrm{N}^{\circ} 64$

Año 2014

\title{
LAS ACTIVIDADES ECONÓMICAS EN EL PALMAR (VALENCIA): ENTRE LA TRADICIÓN Y LA MODERNIDAD
}

\author{
Antonio Bellón Climent \\ Estudiante del Grado en Geografía y Ordenación del Territorio \\ Universidad de Alicante (Alicante, España) \\ Correo electrónico: abc59@alu.ua.es
}

Recibido: 20 de junio de 2013. Devuelto para revisión: 10 de julio de 2013.

Aceptado: 21 de febrero de 2014

\section{RESUMEN}

Se ha estudiado cuáles han sido las actividades que se han realizado de forma tradicional en este núcleo rural y como han influido en el modo de vida de sus habitantes. Luego a través de trabajo de campo se ha comprobado si todo esto coincidía con la realidad actual, y si estas actividades económicas y modos de vida se habían mantenido hasta nuestros días, o si habían quedado subordinadas a otras nuevas relacionadas con el modelo capitalista en el cual nos encontramos inmersos. Por último se ha analizado la dicotomía que pueda darse entre la actividad tradicional y la moderna, es decir entre la pesca y el cultivo del arroz frente a los restaurantes y el turismo, y si la práctica de estas actividades es compatible con el medio ambiente. También se ha seguido en este trabajo cual ha sido el papel de la mujer tanto en el pasado como en el presente, y los conflictos que haya podido generar. 
Palabras clave: Actividades económicas, medio rural, multifuncionalidad rural, trabajo femenino, El Palmar, Valencia.

\title{
ECONOMIC ACTIVITIES IN EL PALMAR (VALENCIAN): BETWEEN TRADITION AND MODERNITY
}

\begin{abstract}
In this work we have firstly analyzed through the study of the works of different authors wish have been the activities were traditionally in this rural area and how these activities influenced in population in daily basis. Later the town was visited during a labor day to check if everything coincided with the present reality and if these economic activities and lifestyles are the same nowadays or if, otherwise, they have to new lifestyles related to the new capitalist model in which are living. Finally, we have analyzed the dichotomy between the traditional activities and the modern ones, that is to say, between the fishing activities or the rice crops and the restaurants or tourism. But also, if these activities are compatible with the environment. In this work we have also studied what is the role of women in the past and in the current society, and the different conflicts that this change may have caused.
\end{abstract}

Key words: Economic Activities, Rural Area, Rural Multifunctionality, Women Employment, El Palmar, Valencia.

\section{ATIVIDADES ECONÔMICAS EM EL PALMAR (VALENCIA): ENTRE TRADIÇÃO E MODERNIDADE}

\section{RESUMO}

Foram estudadas quais foram as atividades que realizaram-se de forma tradicional neste núcleo rural e como influenciaram no modo de vida dos seus habitantes. Então através do trabalho de campo foi comprovado se tudo isto coincidia com a realidade atual, e se essas atividades econômicas e estilos de vida mantiveram-se até hoje em dia, ou tinham sido subordinadas a outras novas relacionadas com o modelo capitalista no qual estamos imersos. Finalmente, analisou-se a dicotomia que pode ocorrer entre a atividade tradicional e moderna, ou seja, entre a pesca e o cultivo de arroz ante os restaurantes e o turismo, e se a prática destas atividades é compatível com o meio ambiente. Também foi visto neste trabalho qual tem sido o papel da mulher tanto no passado como no presente e os conflitos que se possam ter gerado.

Palavras-chave: Atividades econômicas, meio rural, multifuncionalidade rural, trabalho feminino, El Palmar, Valencia. 


\section{INTRODUCCIÓN}

El Palmar es una pedanía que administrativamente pertenece al distrito de Los Poblados del Sur de la ciudad de Valencia, y se encuentra localizada a unos 20 kilómetros al sur de esta. Su emplazamiento lo encontramos en la parte sureste de la Albufera, y fue poblado en sus inicios por pescadores que parece ser que procedían de Ruzafa, Silla y Catarroja, y fueron asentándose en este lugar que hasta casi mediados del siglo XX fue una isla. En total tiene una superficie de 305'8 hectáreas. La pesca en la Albufera ha sido tradicionalmente la actividad más importante. La Comunidad de Pescadores ha sido quien ha organizado la actividad económica y los modos de vida en este pueblo. Los aterraments, que consistieron en la colonización de superficie del lago para la práctica del cultivo del arroz, provocaron que el pueblo se encuentre rodeado de canales y arrozales. La mujer ha luchado para poder realizar la actividad de la pesca, pues ha tenido vedada su participación, estando relegada a un rol secundario. En la actualidad los restaurantes han conquistado este espacio rural, creando un paisaje uniforme por todo el pueblo en el que podemos encontrar numerosos establecimientos donde poder degustar el plato típico del lugar. Este estudio se ha realizado a través de dos métodos, primero se ha recurrido a diversas referencias bibliográficas, y luego se ha completado con el trabajo de campo.

\section{ANÁLISIS DE LAS ACTIVIDADES TRADICIONALES}

Para comenzar en este apartado, se analizarán de forma breve las dos actividades que se han dado de forma tradicional en El Palmar y las relaciones que han tenido con la población autóctona, para que el lector tenga conocimiento de cuáles son las causas que le brindan una singularidad a este enclave. Éstas son la pesca y el cultivo del arroz. Se explicará cuáles son las técnicas que se han empleado en la pesca y sus peculiaridades, y luego se hará lo mismo con los ciclos del arroz. Ambas son actividades que se han complementado temporalmente, pues "los hombres eran medio año pescadores y medio año agricultores" (Viruela, 1995, p. 2), pero en un principio sí que hubo una dicotomía entre ambas, pues para la introducción de los arrozales se hubieron de colonizar superficies de lago, espacios que hasta ese momento se habían dedicado a la pesca. Ambas actividades estaban organizadas por la Comunidad de Pescadores. Esta asociación ha sido quién ha regido la vida social y económica de El Palmar. También se analizará brevemente la importancia que han tenido las herencias, pues han sido la clave de la estructura de la tierra y de la transmisión de los derechos de pesca. Para terminar en este apartado que servirá para tener una idea de cómo ha funcionado la sociedad de El Palmar hasta su apertura al exterior, se analizará el elemento vertebrador de todo este sistema, la comentada anteriormente Comunidad de Pescadores. Este primer apartado ha ocupado una mayor extensión que los restantes, pues para analizar las dinámicas que se han producido desde hace poco más de medio siglo, es necesario explicar cómo era el funcionamiento de la vida tradicional y de las relaciones y actividades que esta conlleva. Para realizar esta parte del estudio se ha tenido el problema de la escasa bibliografía encontrada, aunque se debe destacar el excelente trabajo de Ricardo Sanmartín con $L a$ Albufera y sus hombres (1982), que ha servido de gran ayuda para realizar esta parte del estudio. 


\section{La pesca}

La pesca ha sido la actividad económica más característica de El Palmar. Es una pesca tradicional, en la cual se han utilizado artes artesanales de pesca. La duración es de un día como mucho. Se han practicado principalmente tres tipos de pesca. Éstas son en companyía, al redolí y al involant. Para empezar se analizará de forma breve y muy superficial sus características.

La primera consiste en la pesca mediante grupos, en la cual solían ir dos hombres por barca y en la que pasaban de la decena de barcas por cada grupo. Se basa en cuadrillas organizadas, y se realiza en el interior del lago, pues necesita amplios espacios para moverse con comodidad, se diferencia del tipo de pesca en redolí, en esta que era de iniciativa particular. Es una pesca diurna. Como se ha dicho anteriormente presenta cierto grado organización, que guarda ciertas similitudes con la organización que presentan ciertas actividades agrícolas realizadas en zonas de agricultura intensiva, como por ejemplo la recogida de naranja, en la Huerta de Valencia, en las riberas del Júcar y en la Safor. Entre estas similitudes cabe destacar que ambas se realizan en cuadrillas y hay un cabo que se encarga de dirigir al grupo (suele ser una persona con amplia experiencia en la actividad), son actividades temporales que solo abarcan unos meses del año, y los ingresos obtenidos en cada jornada se reparten entre todos los miembros por igual (cabo incluido). Más adelante se explicará el funcionamiento de cada cuadrilla. Se diferencia del tipo de pesca del redolí, en que esta última es de iniciativa particular, aunque también se pueda dar el caso de realizarla en grupo, sobre todo en los redolins de mayores dimensiones.

La técnica del redolí es un tipo de pesca colectivo que se realiza en los canales, las golas o cerca de alguna mata en el lago. La pesca no se recoge el mismo día, sino que las mallas se dejan por la noche para recoger los peces capturados al día siguiente. Este tipo de pesca origina una zonificación, pues no todas las zonas son iguales y cada redolí tiene un tamaño diferente. Los redolins son puntos fijos de pesca que se reparten antes de empezar la campaña mediante sorteo, que se realiza el segundo domingo de julio en la Junta de Redolins, con lo que se pretende que haya una igualdad de oportunidades. Cada una de estas caladas, se marca con una serie de cañas que se sujetan al fondo, formando el redolí. Alrededor estos se ponen los mornells, que son unas mallas que forman un conjunto de embudos concéntricos sostenidos con unos aros. No todos son iguales, pues los hay mejores y peores. Por este motivo, el día del sorteo era el día festivo local, pues dependiendo del punto fijo que tocara a cada pescador, el porvenir de su familia iba a estar marcado, pues si le tocaba uno de los primeros ese año iba a ser prospero, mientras que si le tocaba una calada mala, le esperaba miseria.

Mientras que la pesca al involant consiste en una pesca libre y autónoma. Es la menos productiva, pues se realiza en la parte occidental del lago, en el lugar que el pescador crea conveniente, en caladas ambulantes, siempre y cuando no sea un lugar marcado. Por tanto siempre se realiza en las zonas pesqueras más pobres. Igual que la pesca al redolí, es una pesca nocturna, pues las redes se recogen al día siguiente.

Entre las principales especies que se han capturado destacamos la anguila, la tenca y la lisa. Se caracterizan porque son especies que salen y entran de la Albufera a través de sus golas, es decir, comparten las aguas dulces del lago con las saladas del mar. Emigran del mar a la albufera en octubre, encontrándose en esta hasta marzo. Una 
característica de esta emigración, es que a mayor mal tiempo, se produce una mayor emigración, sobre todo durante la noche, lo que hizo que hasta hace unas décadas se pescase de noche, a la encesa, es decir con la ayuda de luces, pero este tipo de pesca sólo se realizaba en noches de calma. Esta práctica fue prohibida.

En cuanto a las cuadrillas, cada una tiene su cabo. Se trata de un grupo organizado en el que los que los ingresos se reparten entre todos por igual, inclusive el cabo. Parece ser que esta es la forma más justa de repartir los ingresos, frente a los sistemas actuales del modelo capitalista, en los que existen enormes diferencias salariales. Siempre ha habido conflictos debido a la mayor habilidad de unos pescadores frente a otros, principalmente en la técnica al involant. Mientras que en la pesca colectiva los beneficios se repartían por igual y no se producían estos enfrentamientos. En cuanto a la agricultura, los conflictos han venido por la posesión de la tierra, pues esto creó desigualdades. Estas luchas han venido determinadas a que la propiedad es individual y el lago es de todos, y los resultados de las dos variedades de pesca colectiva se repartían entre todos por igual, cabo incluido, mientras que la pesca individual dependía de la habilidad y suerte de quien la practicara, aunque esta modalidad no producía muchos rendimientos.

Relativamente, la pesca tradicionalmente tuvo un problema, y este consistía en que era una actividad temporal. Pero antes de la "fiebre" por la tierra con los aterraments a finales del siglo XIX y principios del XX, la pesca era la única actividad económica, y por tanto no sólo se realizaba durante medio año, sino que se alargaba la temporada el máximo tiempo posible, y se completaba esta actividad con la caza. Esta era una actividad menor y secundaria. Con la introducción del arroz, la pesca pasó a completarse con esta actividad, para cubrir ambas todo el año sin solaparse entre ellas, con lo que "los hombres eran medio año pescadores y medio año agricultores" (Viruela, 1995, p. 9).

Por último el medio que servía para realizar la actividad, y que también tenía otras funciones, como la de desplazamiento, pues no hay que olvidar que hasta la década de los cuarenta del siglo XX era una isla y el único medio de entrar o salir a El Palmar era con barco. Debido a la poca profundidad que presenta el lago, pues en ningún punto supera los dos metros, y suele quedar situada entre el medio metro y el metro y medio, el tipo de barca prototípico era el barquet, que tenían 20 palmos de eslora, es decir unos cinco metros de longitud y eran movidas por pértigas. En la actualidad las barcas que se utilizan están motorizadas.

\section{La agricultura}

El cultivo del arroz es reciente. A finales de siglo XIX se produjeron los aterraments, que consistían en colonizar tierra del lago para convertirlo en superficie productiva, para el cultivo del arroz. Se hacía mediante el relleno de barro. Se crearon canales para regular el agua. Se crearon normas a través de la Junta General, entre ellas se dictaminaba cual debía de ser el tamaño de las redes, la organización de la actividad agrícola o las zonas de pesca para cada grupo. Existe una zonificación del lago para cada tipo de pesca. En un pasado hubo una dicotomía entre pesca y agricultura, pues se colonizaron superficies de la Albufera que hasta ese momento se dedicaban a la pesca. La apuesta por el arrozal fue tan fuerte que casi un centenar de vecinos se hicieron con el dominio útil de alrededor de 60 hectáreas de suelo. Más tarde, viendo el problema 
que se estaba produciendo, la Compañía de Pescadores repartió las tierras que comprendían la superficie de 250 hectáreas entre los pescadores para evitar que se produjeran más aterraments y que de esta forma no se extinguiese la superficie destinada a realizar su actividad. De esa forma nacieron los tancats. A partir de ese momento la posesión de la tierra va a ser un elemento clave para la distinción social, pues la pesca era un elemento igualitario entre todos los pescadores.

\section{El ciclo del arroz}

Vamos a explicar brevemente la forma tradicional de cultivar el arroz en El Palmar. Tras la cosecha que termina en octubre, un mes después, en noviembre se realiza la perellonà que consistía en abrir las tres compuertas de las tres golas que tiene la Albufera para inundar las tierras. Estas compuertas son la del Perelló, la del Perellonet y la de Pujol y se regulaban para alterar los niveles de agua que entraban y salían del lago hacía el mar. Esta operación solía durar unos dos meses, y con ella se inundaba los campos de forma descontrolada, y permanecían en ese estado hasta que en febrero se secaban las tierras con la aixugà. Cuando ya están secas, ya en marzo, se pone la xiruga, acción que consistía en hacer surcos profundos en la tierra. La siguiente acción es guaretar, que se trata de remover la tierra para que toda ella reciba el sol. Luego se mantorna, que consiste en allanar la tierra con rejas. En la última quincena de este mes se siembra en los semilleros. Estos son pequeñas superficies agrícolas donde se forma la planta. El abonado de las plantas se realiza en abril para luego volver a inundar las tierras, pero esta vez con control. Ya en mayo, la planta que ha crecido en el semillero se trasplanta al arrozal. En junio se realiza el aprimó, que consiste en quitar el agua. A final de mes desaparece toda el agua. En julio se vuelve a llenar de agua con la apertura de las compuertas, lo que hace que esta circule y no se quede estancada. Entonces empieza el periodo de birbar, que abarca los meses de julio y agosto, y consiste en quitar las malas hierbas. Esta tarea era de las más duras y con mayores riesgos debido a los mosquitos, pues en esta época es cuando más enfermedades sufrían, como el paludismo. Esta actividad también se realizaba con cuadrillas. El quitar las malas hierbas era tanto una tarea de higiene para el propio campo como para no dañar la parcela vecina. Al final de agosto se vacía el agua para comenzar a principios de septiembre la siega. Tradicionalmente se ha hecho a mano. Tras la siega, el arroz se lleva al sequer donde se seca a través de la actividad del sol y del viento, que hacen que se vaya dorando. Hay que ir moviéndolo para que no se seque totalmente. El periodo de la plantà es uno de las tareas que más mano de obra necesita, y se realiza mediante cuadrillas con un sistema equivalente al de los pescadores. La forma de realizar esta actividad es en hilera y plantar avanzando hacia atrás. En cuanto al salario, este podía ser tanto a jornal como a destajo.

Todo este ciclo tradicional del arroz quedó en desuso hace unas décadas, alrededor de 1970, con la introducción de la revolución verde, con sus cinco pilares, que son la mecanización, el uso de fertilizantes químicos, y el de productos fitosanitarios, el riego y las semillas seleccionadas. Con estas innovaciones por ejemplo los herbicidas han sustituido a la birba, o la mecanización provocó el excedente de mano de obra. Muchas de las acciones han sido sustituidas por la maquinaria, como la secadora, que se encuentra en la cooperativa y realiza la función que antaño se realizaba con el sequer. 
También es necesario hablar de los problemas que se empezaron a producir de la estructura de la tierra, pues según Sanmartín "35 propietarios no-residentes que constan en 1958, poseían 2.407'5 hanegadas, algo más que la totalidad de los de El Palmar. La mayoría de estos forasteros -que pertenecían a sólo 4 familias- arrendaban la tierra a los de El Palmar" (Sanmartín, 1982, p. 39).

Esta actividad proporcionaba bajos rendimientos, lo que supuso que algunos optaran en determinadas zonas por la sustitución de las tierras dedicadas al arroz por huertos en los que se cultivan hortalizas y legumbres. Aunque se encontraban con el problema del minifundismo, pues estos huertos eran de reducidas dimensiones, aunque los rendimientos eran mucho mayores que en la superficie destinada al arroz.

La Albufera no ha sido el único medio del que se han aprovechado tradicionalmente los habitantes de El Palmar, pues "de la dehesa obtenían leña para la cocina y el invierno, corteza de pino para teñir el hilo de sus redes y estacas para fijar esta en los puntos de calada, clavándolas en el fondo del lago" (Sanmartín, 1982, p. 14). Esta actividad realizada por las gentes del lugar contribuía al mantenimiento de este medio, pues ellos mismos eran los primeros interesados en su conservación.

\section{La herencia}

A la hora de heredar existen dos elementos que forman el patrimonio: la tierra y la vivienda por un lado, y por otra parte la transmisión de los derechos de pesca. Los primeros se dividen por igual entre todos los hermanos, con una mejora para el menor. Esta mejora puede ser la casa en la que vivían los padres o la tierra que tenían arrendada. Todo lo demás se reparte por igual. Esto se entendía porque supuestamente los hermanos mayores ya habían formado su propia familia y habían abandonado el hogar y era el pequeño el que se quedaba cuidando a los padres hasta última hora y esta mejora era como una especie de compensación. Los hijos son los que trabajaban la tierra, y por tanto cada uno significaba dos brazos más para ayudar en las labores. El problema venía cuando no había hijos, o había más hijas que hijos. Un tema de conflicto era que en el reparto equitativo, las hijas recogían la misma parte que los hijos. Y el problema es que podían surgir recelos entre ellos, pues los hombres son los que trabajaban la tierra y ellas no lo hacían, y aun así les correspondía una parte de esta, y esto podía crear problemas entre cuñados.

En cuanto a la herencia a los derechos de pesca, se ha utilizado el término de redolí para estos mismos, de los que son poseedores cada miembro de la Comunidad de Pescadores. Este se conserva hasta la muerte, la jubilación, la expulsión de la Comunidad o la transmisión a un hijo que cumpla los requisitos. No hay que confundir este término que hace referencia a un derecho con el que hace referencia a un punto fijo de pesca durante un año y designado mediante sorteo, y que hemos explicado anteriormente. Para permanecer como miembro de la Comunidad hay que abonar una cantidad anual. Se puede tener redolí activo, abonando la cuota anual y se obtiene el derecho a participar en el sorteo para obtener el punto fijo de pesca para ese año. O el redolí puede ser pasivo si no se entra en el sorteo, pero ha de pagar una tercera parte de esa cantidad para seguir siendo miembro, y esta persona entonces puede pescar tanto al involant como en companyia. Tras cinco años sin abonar el pago se pierde el derecho, y los descendientes 
de este lo pierden también. Cada miembro de la Comunidad tiene un heredero, pero sus otros hijos también pueden obtener un redolí, pero estos a diferencia del que lo adquiere por herencia han de pagar una cantidad económica por él. Si se muere sin haber constado de quien será el heredero, estos derechos pasarán al nieto mayor. Se ha podido dar el caso que una persona sea el nieto mayor por parte paterna y materna, con lo cual solo podría heredar un redolí y habría que elegir cual. En caso de que no hubiera nietos todavía, el heredero es un hijo. Pero con el fallecimiento del pescador, aunque el heredero por ley es el nieto mayor, el redolí pasa a ser titularidad de la viuda. Esta no puede pescar ni asistir a las juntas. Por tanto es un derecho de usufructo indirecto, que ha de ceder a algún familiar.

La venta del redolí ha estado prohibida. Esta medida defiende el carácter cerrado de la Comunidad respecto al exterior, (esta medida sirve de defensa para la entrada de capitales exteriores que si se introdujesen en este modelo aislado destruirían su identidad histórica). Esto ha contribuido al aislamiento de este pueblo, junto al medio físico, pues como ya hemos comentado, hasta hace poco era una isla y para entrar y salir de ella había que hacerlo en barca.

\section{La comunidad de pescadores}

El Palmar ha sido un núcleo rural que se ha caracterizado siempre por su aislamiento respecto al exterior. El verdadero motor de la vida en este enclave ha sido la Comunidad de Pescadores, que ha sido un elemento clave para este aislamiento debido a su hermetismo, basado en las leyes consuetudinarias en las que se basa. Se compone de varios órganos ${ }^{1}$. Estos son la Junta General, en la cual se reúnen sus miembros de forma ordinaria tres veces al año para elaborar las normas y tomar decisiones, y también pudiéndose reunir de forma extraordinaria; la Junta Directiva que ejecuta las decisiones tomadas en la anterior, formada por dos vocales, un tesoreros y dos secretarios, presididos por un jurado primero y segundo; el Consell Assessor, que tiene carácter consultivo y también resuelve los litigios que se puedan producir entre pescadores, o entre la pesca y el cultivo del arroz; y la Comissió de Compraventa, que más adelante explicaremos. Mención especial merecen la Junta de Capítols, que se realizaba el primer domingo de julio y en la cual se revisaban las normas y elaborar nuevas si era necesario, no pudiéndose modificar estos hasta el año siguiente, y en la cual se fijaban los redolins para esa temporada; y la Junta de Redolins que se realizaba al domingo siguiente y que era el día más importante del año para los habitantes de El Palmar porque en ella se sorteaban los redolins para esa temporada.

Se han de cumplir dos variables básicas para ser miembro de la Comunidad: ser hijo de pescador, y tener 24 años o haber contraído matrimonio. Destaca la rigidez en cuanto al cumplimiento de su normativa. Por ejemplo esto se aprecia en la negativa a la entrada de la mujer como miembro o la denegación de propuestas para formar un redolí nuevo de personas que lo han solicitado ante la Junta de Capítols, debido a que era quién tenía que mantener una familia debido a su situación de orfandad y su solicitud fue denegada por no tener la edad. O también cuando algún miembro no había pagado su cuota,

\footnotetext{
${ }^{1}$ Para profundizar en el estudio de la Comunidad de Pescadores de El Palmar, ver Sanmartín, R. La Albufera y sus hombres. Madrid: Akal Editors, 1982, p. 151-211.
} 
aunque fuese porque debido a sus circunstancias económicas realmente no pudiese, y no se le dejaba participar en el sorteo de la Junta dels Redolins, con lo cual ese año no iba a tener redolí, y con esta medida aumentaría su desgracia. Todo esto puede entenderse como que es una forma para mantener viva la Comunidad.

Esta se financia a través de lo que abonan sus miembros, como las cuotas trimestrales que abonan quienes tienen su redolí, el pago que realizan los que pescan por su cuenta, es decir al involant, y que es bastante menor la cuantía económica que la anterior, y también el pago que realizan los aprendices por pescar. También se financian con las multas que se paga por las infracciones. Y desde su creación, en 1949, también con los beneficios que obtiene la Secció de Compraventa. Esta se creó para hacer frente a los revendedores. En años de déficit en las cuentas de esta, entre las medidas tomadas para equilibrar la balanza han sido el descenso de los precios pagados a los pescadores por las capturas, o el aumento de las cuotas trimestrales, lo que ha supuesto conflictos. Estas decisiones, como veremos en otros apartados, tendrán gran trascendencia en el futuro del sector.

El sorteo para asignar los redolins de cada año, se realiza para evitar los conflictos por los puntos más buenos de pesca, debido a que hay puestos mejor que otros. De esta manera, es el azar quien decide la suerte del pescador para ese próximo año. En teoría se ha vendido tradicionalmente que esto es una forma más de representar la equidad entre todos sus miembros que pretende conseguir la Comunidad, pues argumentan que es la suerte a través de un sorteo y no una decisión quien marca el porvenir de ese año del pescador. En cualquier caso, esto no es justo del todo, pues a un mismo pescador le pueden tocar varios años seguidos un punto fijo de peor calidad el cual le pueda llevar a sufrir una crisis económica, y pensamos que un sistema más justo para hacer el reparto en el cual el azar no condenase a nadie, hubiese sido coger los redolins más productivos y los peores, y en estos ir rotándose durante breves periodos de tiempo todos los pescadores, de esta manera todos pasarían por los buenos y por los malos.

Existe cierta similitud en la Comunidad con una cooperativa agrícola, en algunos aspectos, pues un principio básico es el reparto equitativo entre todos sus miembros, y todos los miembros se llevan los mismos beneficios, y en momentos de crisis sí hay que tomar una decisión y ésta puede alterar el funcionamiento de la Comunidad de Pescadores, afecta a todos por igual, teóricamente. También tiene carácter democrático y los acuerdos son tomados por mayoría. Piensa en el bien colectivo y no en el individual. También ambas son organizaciones creadas por los pescadores/agricultores y en las que la pertenencia a ellas está relacionada con la posesión de la tierra, pues por ejemplo en el caso de los pescadores de El Palmar, la Comunidad hace poco más de siglo "para no dejar de serlo, se hicieron, además agricultores" (Sanmartín, 1982, p. 46) mediante los aterraments, repartiendo la tierra entre los miembros de la comunidad de forma equitativa. Mientras, en el caso de las cooperativas agrícolas, podemos destacar las que encontramos en la Ribera Alta relacionadas con el cultivo cítrico, en las cuáles para ser miembro de ellas has de ser propietario de tierras. La diferencia entre ambas organizaciones es que mientras que en el caso de El Palmar "la pertenencia a la Comunidad de Pescadores permitió el acceso a la tierra" (Sanmartín, 1982, p. 46), siendo este el origen de las posteriores diferenciaciones sociales, mientras que en las cooperativas agrícolas comentadas, se daría el caso contrario, es decir, "la propiedad de las tierras permite la pertenencia a la Cooperativa". 


\section{EI TIPO DE VIVIENDA}

El tipo de hábitat tradicional desde los primeros asentamientos ha sido la barraca. Este tipo de vivienda se ha asociado a un tipo de hábitat de pescadores, pues se podía encontrar también en otros lugares donde la actividad económica tradicional era la pesca, como por ejemplo El Cabañal o Pinedo.

Se caracterizaba por tener dos muros muy bajos en ambos laterales, entre 1'5 y 2'5 metros. Luego un tejado a dos aguas de paja. La parte más alta, en ese punto donde se encuentran ambas partes del tejado lo encontramos a unos 6 metros de altura aproximadamente. Pese a que no todas las barracas tenían las mismas medidas y dimensiones, su longitud generalmente era de unos 10 metros mientras que su anchura se encontraba entre 4'5 y 6'5 metros. En cuanto a su interior, solía contener dos dormitorios Era el hábitat típico hasta el siglo XIX, en el cual empezó a producirse su decadencia, que se manifestó sobre todo hasta el incendio de 1885 en el que se destruyó parte del pueblo, y a partir de ese hito cronológico, se empezaron a construir todas las viviendas dañadas con ladrillo. De esta forma han ido desapareciendo y hoy dentro del pueblo solo encontramos dos barracas, solo una de ellas original, aunque sí que encontramos diversas barracas dispersas en la parte occidental de la carretera que lleva al pueblo, cada una de ellas rodeada de su huerta. Se debería de preservar este tipo de vivienda ya que representa un patrimonio histórico, y que hoy se encuentra en peligro de extinción, y que entre las medidas que se podrían tomar para evitar su desaparición del paisaje sería la construcción de este tipo de viviendas que representan el modelo tradicional del lugar.

Una característica de las barracas de El Palmar es que existían barracas de culata, que eran únicas de este lugar, pues no se encontraban en otros emplazamientos de pescadores. Estas caracterizaban porque la parte trasera terminaba en forma de abciso. A lo largo de la puerta que daba a la calle encontrábamos un pasillo longitudinal, y a la otra parte en el centro estaba la sala de estar, con un banco, y en ambos ángulos los dos dormitorios.

Algunas hipótesis hablan de un origen palafítico de este tipo de vivienda en este espacio, es decir que se encontraban sobre el agua, pero sin que tuvieran en ningún momento contacto ni la vivienda ni el agua, pues la vivienda se sostenía sobre unos palos por encima del agua. Estas teorías sostienen que más bien eran barracas-viveros, que desaparecieron debido a su poca practicidad, pues tenían el problema que debido al ciclo del arroz se inundaban al subir el nivel del agua.

Una barraca palafítica se caracteriza porque ni el agua ni el habitáculo están en contacto. Según J. L'Escrivà (1986, p. 36) "la barraca semipalafítica de la Albufera no tiene esas condiciones de habitabilidad", pues el ciclo del arroz haría que en algunas épocas del año pueda subir el nivel del agua llegando hasta el habitáculo.

En su origen los materiales eran cañas y barro. La caña en las primeras construcciones era un material elemental, pero conforme va evolucionando este tipo de vivienda pasa a ser un material secundario. Mientras que con el barro pasa lo mismo, pues más adelante pasara al ladrillo. En cuanto a su forma "si pedimos a un niño que dibuje una casa, lo veremos representarla gráficamente con cinco líneas. Dos verticales, paralelas, que sostienen a otras dos en ángulo invertido. Es decir es el esquema más sencillo para 
representar una casa y fue el que utilizaron los agricultores para levantar sus viviendas" (L’Escrivà, 1976, p. 53).

Otra característica de esta vivienda es que no existe espacio en el interior para los animales. Estos se encontraran en el exterior, en unos espacios adyacentes que se pueden localizar tanto detrás como delante, o a un lado de la barraca. Según L'Escrivà (1976), el nacimiento de la segunda barraca se debe a que el espacio de separación entre ambas viviendas se aprovechaba para el ganado.

En su origen, los muros laterales eran más bajos, alcanzando como máximo los 40 centímetros de altura. Conforme fue evolucionando fueron creciendo hasta llegar a los 2'5 metros. Estos cambios buscando alcanzar cada vez más mayor altura se realizaron «siempre buscando la máxima habitabilidad interior» (L'Escrivà, 1976). Junto al cambio en la estructura, que provocó cambios en el interior, también se produjeron cambios en el mobiliario interior.

J. L'Escrivà (1976, p. 75) dice que "la cubierta marca el carácter rural de esta clase de habitáculo, en su aspecto físico externo, más que ningún otro detalle”. Tiene forma a dos aguas, y está cubierta de paja. Este material es muy susceptible al fuego, y tras el incendio del año 1985, fueron sustituyéndose este tipo de viviendas por las de piedra, pues estas garantizaban mayor seguridad. Aunque esto le resto "autenticidad" al lugar. Hoy los edificios que representan este tipo de edificación, están cubiertos por materiales modernos como por ejemplo la uralita. Por encima de esta aparecen una serie de barras metálicas, en las cuáles se "teje" la paja, para darle ese carácter rural y tradicional.

Este tipo de barracas modernas son construidas por personas alóctonas. Son las que encontramos en las cercanías del pueblo, y ya no tienen las mismas funciones que las tradicionales. Son "barracas-chalet” (L'Escrivà, 1986, p. 106). Ya no es el lugar del agricultor tradicional, pues ahora tiene una función residencial, nostálgica de recuperación de un elemento autóctono del pasado. En cuanto a la barraca que queda original dentro del pueblo, es una barraca "fosilizada", y que ha quedado como sede de la Comunidad de Pescadores.

La introducción del capitalismo produjo cambios sociales, pues con la generalización del cultivo del arroz con el aumento de las tierras dedicadas a este, ahora se va a producir una diferenciación social según las tierras que se posea. Con estos cambios ahora un habitante de El Palmar podrá ser propietario.

\section{CARACTERÍSTICAS ACTUALES}

En este apartado se analiza la situación actual de este pueblo. En los dos primeros subepígrafes se estudia tanto las características demográficas como las socioeconómicas. Para la obtención de los datos estadísticos empleados se ha recurrido a la Oficina de Estadística del Ayuntamiento de Valencia. El contenido del siguiente subepígrafe se basará en el trabajo de campo, describiendo las características que nos encontramos en nuestra visita a esta pedanía y detallando nuestras percepciones. 


\section{Características demográficas}

En el año 2012 contaba con 748 habitantes, de los cuales 360 son varones, mientras que los restantes, 388 , son mujeres.

Pese a que en este subapartado se pretende analizar las características demográficas, para su explicación no debemos obviar algunos datos relacionados con la actividad económica, pues las variaciones que se hayan podido producir en los sectores económicos son un factor clave para las variaciones demográficas, pues influyen directamente en los movimientos migratorios. Hoy en día el porcentaje de población que se dedica a las actividades del sector primario, principalmente a la pesca, ha reducido mucho, pues "es una actividad marginal a la que se dedican muy pocas personas" (Viruela, 1995, p. 12), y ha crecido mucho el porcentaje dedicado al sector terciario, por lo tanto podemos hablar de que se ha producido una terciarización de la actividad. Entre las causas de la crisis pesquera podemos destacar la contaminación causada por la introducción de fertilizantes químicos y productos fitosanitarios con la revolución verde, y del binomio industrialización-urbanización, que han provocado la reducción de los peces en el lago. Pero la principal causa ha sido que desde la segunda mitad de siglo XX, los beneficios obtenidos por los pescadores iban disminuyendo cada vez más debido que los precios que obtenían por sus capturas iban cada vez a menos mientras que las cuotas trimestrales aumentaban. En cuanto a la actividad dedicada al arroz, la introducción de la mecanización ha supuesto que sobre de mano de obra para la agricultura, y también contribuyo al aumento del trabajo a tiempo parcial, pues con esta innovación la productividad aumenta con menos horas de trabajo. Con todo esto se ha ido produciendo un descenso de la población desde mitad de siglo XX, que provocó la emigración de muchos jóvenes. Tenemos que destacar el proceso de pérdida de población que se ha ido produciendo en las últimas décadas, pues en 1981 la población era de 925 habitantes, mientras que en 2012 esta había descendido a 748 (Véase el Cuadro 1). También destacar la baja densidad, pues en el año 2012 era de 2 '4 habitantes por hectárea.

Cuadro 1. Evolución de la población en el Palmar

\begin{tabular}{|c|c|c|c|c|}
\hline Año & 1981 & 1996 & 2012 & Var. 1981-2012 \\
\hline Población & 925 & 895 & 748 & $-19,81 \%$ \\
\hline
\end{tabular}

Fuente: Oficina de Estadística del Ayuntamiento de Valencia.

Elaboración propia

A partir de mediados de siglo XX disminuye la población, pues a partir sobretodo de 1960 tanto la agricultura del arroz como la pesca entran en crisis, que combinados al auge en esta década del crecimiento urbano y la industrialización contribuyen a que mucha gente de El Palmar tenga que emigrar. Este crecimiento urbano y de la industria, no solo tendrá consecuencias demográficas, sino que como más tarde en otro epígrafe analizaremos, debido a que las zonas limítrofes con la Albufera experimentan un gran desarrollo tanto en industria como en el crecimiento de las poblaciones, esto va a tener repercusiones en el medio de trabajo de esta comunidad a través del aumento de los vertidos que contaminaran el lago, pues, que hará disminuir los rendimientos de la pesca. 
La introducción de la mecanización con la revolución verde con el fin de aumentar la producción hará que sobre mano de obra. Esto se aprecia con la introducción de las cosechadoras, que sustituyen al trabajo manual en la siega del arroz en septiembre, y que era una de las actividades que más mano de obra requería. Esta introducción trajo consigo la reducción del tiempo de siega, que antes de esto eran unos 25 días, y la de la mano de obra necesaria. El uso de herbicidas y plaguicidas será un factor que contribuirá, junto a los anteriormente comentados, a la contaminación del lago. Aquí tenemos otro caso en el que se produce una dialéctica entre los dos usos de suelo agrarios que han dominado la vida de este pueblo, pues la introducción de medidas químicas para mejorar el cultivo del arroz, propiciaron la contaminación del medio del cual se abastecía la otra actividad, provocando la disminución de las especies, que traerá un descenso de las capturas, pues "la crisis pesquera se atribuye a los devastadores efectos de la contaminación” (Viruela, 1995, p. 11).

Por lo general, en los espacios rurales se suelen dar una serie de características sociodemográficas, como son el envejecimiento de la población, con la pérdida de población joven, la "masculinización", es decir la mayor proporción de hombres que de mujeres, o un crecimiento vegetativo negativo, debido a la disminución de la fecundidad y el aumento de la mortalidad debido al incremento de la esperanza de vida y la mayor proporción de población en edad vieja. Actualmente entre estas características sociodemográficas que dan en este núcleo, encontramos tras hacer un análisis, que muchas de ellas son las propias del mundo rural anteriormente comentadas. Entre estas destacamos el envejecimiento de la población. En 2012, a través de los datos obtenidos en la Oficina de Estadística del Ayuntamiento de Valencia, vivían en el pueblo 218 personas mayores de 65 años, un 29'1\% de la población. El dato es destacable, pues casi una tercera parte de los habitantes están en edad de jubilación.

El índice de masculinidad en el año 2012 fue de 92'7 hombres por cada 100 mujeres, algo menor que el de la media nacional. En cuanto a otras características llama la atención que no existe "masculinización" en la tercera edad, pues los hombres mayores de 65 años son 99 mientras que las mujeres 119, por tanto la sex ratio sería de 83'1 hombres por cada 100 mujeres. Otro dato curioso, es que entre las 16 personas mayores de 84 años, ambos géneros se repartían de forma equitativa, es decir 8 y 8 , algo no muy habitual pues la mujer tiene una esperanza de vida mayor que la del hombre.

Un último aspecto rural que se observa es que hay un crecimiento vegetativo negativo. Con los datos de la Oficina de Estadística del Ayuntamiento de Valencia del año 2012 ${ }^{2}$, se observa que las muertes superaron a los nacimientos, con cuatro nacimientos y cinco defunciones, y por tanto tendríamos una tasa de natalidad de $5,34 \%$, mientras que la de mortalidad es de 6'68\%. Por tanto, el saldo fue negativo, con $-1{ }^{\prime} 34 \%$.

\footnotetext{
${ }^{2}$ Para consultar los datos estadísticos de El Palmar, consultar la Oficina de Estadística del Ayuntamiento de Valencia, en distritos, barrios, Poblados del Sur, El Palmar.
} 


\section{Características socioeconómicas de la población}

En el año 2001, la población activa estaba formada por 342 personas, de las cuales 219 eran hombres, mientras que 123 eran mujeres. A través de estos datos podemos ver cuál era la situación en cada sector de actividad de los que nos interesa para nuestro estudio. Ese año, solo 40 personas se dedicaban a la agricultura o a la pesca, cosa que nos muestra la poca relevancia que tienen estas actividades en la actualidad. 36 de ellas eran hombres, mientras que solo 4 eran mujeres.

Muchos de los que se encuentran en el grupo de población en edad de jubilación, no obstante de esta circunstancia, se dedican a la pesca, debido a las nuevas pautas de vida de las nuevas generaciones con el descenso del número de hijos, que propicia que muchas personas jubiladas tengan que dedicarse a las tareas de la pesca para añadir ingresos económicos, pues es "la ausencia de los hijos lo que les obliga a mantenerse activos y sobre todo las miserables pensiones de jubilación" (Viruela, 1995, p. 16). Por tanto, según este autor, son dos elementos los que propician que muchos habitantes en edad de jubilación se dediquen a pescar, la disminución en el número de hijos debido a la reducción de la tasa de fecundidad y las bajas pensiones de jubilación frente al cada vez más elevado nivel de vida.

En cuanto a la otra actividad que interesa, la hostelería, comprendía a 97 personas, de las cuales 47 eran hombres y 50 mujeres, pues desde hace unas décadas «restaurantes y cafeterías emplean a la mayor parte de los trabajadores» (Viruela, 1995, p. 6). El resto de la población activa se repartía entre la construcción, la industria o se dedicaban a profesiones tituladas. Estos datos, aparte de mostrar el peso de cada actividad, pueden servir para ver cómo la mujer aquí no tiene cabida (como ha sido históricamente) en las actividades del sector primario, mientras que su entrada en el mundo laboral, pese a que antes ya realizaba tareas de forma auxiliar al marido tanto en el ciclo del arroz como en la pesca, está relacionada con la aparición de la hostelería.

Se ha producido un proceso de "desagrarización" puesto que los principales ingresos ya no proceden ni de la agricultura ni de la pesca, cuando ambas han sido hasta hace poco la fuente de los ingresos locales. Ahora proceden de los numerosos restaurantes que se encuentran por el pueblo, y de las visitas guiadas en la cuales destacan los paseos en barca por la Albufera. Esta ha pasado de ser un bien de producción, de la cual se obtenían las capturas pesqueras, a convertirse en un bien de consumo. Hoy con esta subordinación "la pesca es una actividad marginal a la que se dedican muy pocas personas" y ¿"son escasos los pescadores puros, sólo quienes se han jubilado de su ocupación principal trabajan exclusivamente en la pesca"? (Viruela, 1995, p. 12). También en la actualidad hay que tener en cuenta otro aspecto importante, y es que el paro es un elemento clave para determinar el número de pescadores en el sorteo de redolins en un año concreto, pues es como un péndulo que marca el mayor o menor número de estos, ya que muchos jóvenes se dan "de alta porque se encuentran en paro" (Viruela, 1995, p. 18). Pero esto pretenden realizarlo de forma transitoria, pues no tienen intención de permanecer mucho tiempo es esta actividad.

En cuanto a las actividades relacionadas con la restauración y el turismo, se ha aprovechado para vender con el lema de "el corazón de la gastronomía valenciana" y se han aprovechado para vender visitas en barca como en "Cañas y barro", con diversos embarcaderos particulares a la entrada del pueblo, como por ejemplo el de Rosa la 
barquera y Tonet, en el cual un día laboral reciben numerosas visitas de colegios. Este marketing se aprecia en carteles que se pueden encontrar por el pueblo, como el que aparece en el parking que hay en la entrada del pueblo, o también a través de internet, pues si se realiza una búsqueda de El Palmar por la web, toda la información que aparece está relacionada con restaurantes.

Por lo tanto, con la introducción del capitalismo en este mundo hasta ese momento aislado, han surgido nuevas actividades, como son la gastronomía y el turismo rural. Por lo que se observa, en cuanto al turismo, es que no se trata de un turismo de masas (bueno aunque esto puede ser relativo), sino que se puede observar dos clases de turismo. Uno suele ser un turismo de fin de semana, mientras que el otro es un turismo de días laborales. En el primero se encuentra un turista que viene atraído por la gastronomía del lugar. Suele ser mayor el número de este tipo de turistas el fin de semana, principalmente el domingo. Estos vienen en su vehículo particular, almuerzan o comen, y tras esto abandonan el pueblo. Suelen dejar bastante dinero en el lugar. Mientras que la otra modalidad, son aquellos turistas que vienen de excursión a pasar el día a través de un viaje organizado con una visita guiada. Vienen en autobús, y según lo observado en nuestra visita a El Palmar, son o bien escolares o bien jubilados. Vienen entre semana. Aunque los jubilados también pueden llegar el fin de semana.

\section{Perspectiva actual del pueblo}

Para llegar a El Palmar se ha de atravesar una carretera, a la cual se accede en la CV500, y que sigue a través de una dirección norte-sur, en la cual encontramos tres puentes. Estas infraestructuras fueron las que hicieron que dejase de ser una isla hace poco más de medio siglo. Al lado de la carretera, antes de llegar al pueblo, ya empiezan a aparecer campings y restaurantes de forma dispersa. Conforme el pueblo está más cercano, encontramos viviendas en forma de barraca con su huerta alrededor.

En su origen, el tipo de vivienda fue la barraca. Pero tras el incendio de 1885, se reconstruyó toda la parte del pueblo dañada con viviendas de piedra. El Palmar cuenta con un alcalde de pedanía y ayuntamiento. El núcleo presenta un plano lineal, a través de 2 calles paralelas, que van a parar tanto por el norte como el sur de su recorrido a la plaza, a modo de bifurcación. La plaza ha sido y es el centro neurálgico, siendo el origen y el destino de cualquier acto realizado en el pueblo, en ella se encuentra la iglesia del Niño Jesús del Huerto, amén de que es uno de los lugares donde encontramos mayor concentración de restaurantes del núcleo.

Las viviendas están orientadas de este a oeste, y se encuentra rodeado de canales, tanto por el este como por el oeste, que "han sido la salida normal del pueblo, de ahí que al canal este le llamen port de baix y al del oeste port de dalt" (Sanmartín, 1982, p. 15), y ambos son el borde físico que ha limitado el crecimiento a lo ancho del pueblo. La toponimia refleja la importancia que ha tenido la pesca, pues por se observa por ejemplo en la Plaça de la Sequiota, que es el corazón del núcleo, y hace referencia a la Sequiota, que es el mejor punto fijo de pesca, es decir el mejor redolí y que proporcionaba riqueza al agraciado al que tuviese la fortuna de salir su nombre en la primera papeleta del sorteo. O también en algunas calles con nombres que hacen referencia a la pesca como carrer dels Redolins. 
La entrada del pueblo, la encontramos en la parte norte, a la izquierda de la cual, aparece un gran parking, para los autobuses que traen a los visitantes. Frente a este, en el borde occidental encontramos los embarcaderos. Justo en la entrada del pueblo, en la calle Baldoví, encontramos algunos equipamientos como un colegio, un parque y la piscina municipal. En esta zona norte, prácticamente todas las viviendas se encuentran en muy buen estado. Dentro del pueblo encontramos muchísimos restaurantes, es el elemento más común. En ellos el plato estrella es el all i pebre, que se trata de un guiso que se ha venido haciendo de forma tradicional, y se realiza con anguilas recién muertas, y que se completa con ajo y pimienta. Llama la atención que dentro del viario aparecen dos edificaciones con tipología de barraca.

A la orilla del canal del este encontramos casas que están en mal estado. Son viviendas que por su aspecto y morfología muestran mayor antigüedad, pues en ellas se observan espacios internos de la vivienda como los corrales que tradicionalmente han tenido la función de albergar a los animales, pues muchas de ellas "tienen en su parte trasera un pequeño corral" (Sanmartín, 1982, p. 14). En la actualidad esta parte de la casa presenta otras funciones. También se observan junto al canal los arrozales. No siempre ha presentado este aspecto, pues esto era lago, pero que por obra de los aterraments, se produjo un cambio de paisaje y de función.

Por el contrario, la calle Cristo Santísimo de la Salut, junto al canal de la parte oeste, se podría decir que es la calle comercial, pues en casi todos los bajos hay restaurantes. El centro y corazón del pueblo es la Plaça de la Sequiota, donde se encuentra la Iglesia parroquial del Niño Jesús del Huerto, alrededor de la cual tradicionalmente ha girado la vida de la población. En ella también hay muchos restaurantes y mesas en el exterior. Ambos espacios es donde aparecen mayor número de restaurantes. Más allá de la plaza, hacía el sur, la mayoría de los edificios se encuentran en estado más anticuado. Por todo el pueblo aparecen carteles en los que se puede leer "paseos en barca". En esta parte del núcleo encontramos una Lonja, en la que se venden los productos típicos del lugar como son las anguilas, lisas y tencas.

Se observa que perduran costumbres tradicionales del mundo rural como tener macetas en la calle o las ventanas, y tender la ropa en la calle, principalmente en las calles en las que no hay restaurantes. En la parte meridional de la calle Santísimo Cristo de la Salut ya no encontramos apenas restaurantes. Muchas casas que no han sido reformadas conservan la estructura tradicional, con viviendas de una sola planta. Los negocios que encontramos, que no sean restaurante, pues la gran mayoría lo son, son de tipo familiar, de trato directo. También se observa que la mayoría de la población habla en valenciano. Según los datos de la Oficina de Estadística del Ayuntamiento de Valencia, en el año 2001 solamente 40 personas no lo hablaban. Lo que más llama la atención, a parte de los numerosos restaurantes que encontramos en el pueblo, es el "paisaje de mesas exteriores" en los restaurantes, pues con probabilidad habrán más mesas en las calles que casas en todo el núcleo. 


\section{EL PAPEL DE LA MUJER EN LAS ACTIVIDADES ECONÓMICAS}

En este apartado se analizará el papel que ha tenido la mujer en la actividad económica y la lucha social que se ha producido por acceder al derecho del redolí, que le había sido negado desde la fundación de la Comunidad de Pescadores, alcanzando el momento de explosión en el año 1997 cuando algunas mujeres que reclamaban este derecho recurrieron a la vía judicial, desatándose un conflicto, del que bien se habría podido hace un trabajo entero, pero que debido a que el objetivo de esta investigación es analizar los cambios sociales y económicos que se han producido en El Palmar de manera general, y no solo de manera concreta los que han afectado a la mujer y a su papel en la actividad económica y social, solo se ocupara una páginas este tema.

Tradicionalmente, las mujeres también han participado en las actividades, aunque de forma secundaria y subordinada a la actividad del hombre. En la tarea del arroz solamente ayudaban en el sequer, pero en la pesca su colaboración era mayor, pues la actividad de tejer las redes correspondía a ella. Las dimensiones de las redes venían dictaminadas por las normas de la Comunidad de Pescadores. También colaboraban en la venda del pescado, tanto en puestos fijos en el Mercado de Ruzafa como recorriendo pueblos cercanos mediante venta ambulante. Ya que era una isla, hasta mitad de siglo $\mathrm{XX}$, para vender el pescado o para abastecerse de productos, era necesario cruzar el lago en barca, hasta que en 1949 se creó una comisión encargada de comprar el pescado a los pescadores y comercializarlo en el mercado, fijando los precios de compra, y a la cual estaban obligados los miembros de la Comunidad a vender bajo pena de ser expulsados de esta.

En cuanto al tema de la pesca, las mujeres han intentado introducirse en varias ocasiones en la Comunidad de Pescadores de El Palmar para poder pescar en la Albufera de Valencia, pero ninguna con éxito. Esto se debe a las normas de la Comunidad de Pescadores, que como comentaremos más adelante nombran sólo a los hijos de patrón de la misma, excluyendo de esta forma por completo al género femenino. Esto es un claro ejemplo de cómo no toda la sociedad evoluciona y sigue existiendo diferencias de género.

Si se analiza el papel que ha venido teniendo la mujer en cuanto a la actividad económica, observamos que ha existido una discriminación por sexo. Ésta viene porque la Comunidad de Pescadores basándose en el derecho consuetudinario, con el pretexto de que es una institucional tradicional que respeta su historia y tradición, ha impedido desde sus inicios la entrada de la mujer para formar parte de esta institución, impidiéndole la herencia del redolí, aunque bien es cierto que sí que podían transmitir este derecho en algunos casos concretos. Pero hubo mujeres que no se contentaron con esta situación y lucharon por cambiarla.

Ha habido una lucha por conseguir una igualdad, recurriendo para lograrla a la vía judicial, cuando algunas mujeres que eran hijas de pescadores intentaron ingresar en la comunidad, y su petición fue rechazada. La comunidad no quiso abrirse y pretendió a toda costa mantener el hermetismo que tenía desde sus inicios, manteniendo una discriminación sobre la mujer. Esta lucha femenina recibió apoyo de fuera del pueblo. Aunque no todas las mujeres de El Palmar estuvieron a favor de esta apertura y realizar cambios, pues hubo quienes estuvieron a favor de mantener la tradición de la Comunidad de Pescadores intacta. Por tanto se empezó a crear una dicotomía dentro del 
mismo género femenino, donde cada grupo tuvo sus instituciones de apoyo. Las mujeres que solicitaron una apertura de la comunidad, derribando el muro que había creado desde sus orígenes esta institución y que se materializaba en la persistencia de la mujer ya en tiempos democráticos, aspirando a una igualdad, fueron apoyadas por la asociación de amas de casa de Valencia Tyrius. Por otro lado, se creó una asociación, Mujeres Independientes del Palmar, que apoyaba a las mujeres que apoyaban a mantener la negativa a la entrada de la mujer en esta actividad. Este hecho ha provocado que se haya producido en la actualidad un pequeño cambio en cuanto a la lucha social interna de este pueblo, pues ahora esta lucha ya se da dentro del mismo género femenino.

El conflicto se magnificó con la introducción en este de elementos de apoyo externos, como asociaciones, grupos políticos y sindicatos, y algunos medios de comunicación.

En 2007, tras varios intentos de ingreso por parte de las propias hijas de pescadores y numerosos rechazos por la tradición que caracteriza a la Comunidad de Pescadores, las mujeres se vieron obligadas a tomar medidas judiciales ante el Tribunal Supremo, apelando al artículo 14 de la Constitución «Los españoles son iguales ante la ley, sin que pueda prevalecer discriminación alguna por razón de nacimiento, raza, sexo, religión, opinión o cualquier otra condición o circunstancia personal o social». Finalmente, y después de varios procesos judiciales, se permitió a las féminas formar parte de la tradición de la Comunidad de Pescadores de El Palmar, a pesar de que ésta no compartiera la decisión del Tribunal, ya que su ingreso cambiaría por completo las costumbres que caracterizaba esta actividad piscícola desde el año 125.

Por tanto ha habido una lucha de las mujeres contra la historia del pueblo, que ha venido marcando las relaciones sociales, y que era una historia injusta basada en el conservadurismo y la discriminación, de la cual su principal víctima ha sido la mujer, relegándola a un elemento secundario en la actividad pesquera. Una buena forma de concluir este apartado sería señalando con la obtención gracias a los tribunales de este derecho se ha conseguido un gran logro para la mujer y para la sociedad.

\section{ACTIVIDADES TRADICIONALES Y TERCIARIZACIÓN DE LA ECONOMÍA: CONFLICTO DE INTERESES}

En la segunda mitad de siglo XX, con la crisis de la pesca en el lago unido a la subida de las cuotas trimestrales provocan que muchos redolins tuviesen que ser depositados para buscar empleo en otra actividad. De los que se mantienen en el sector se ha producido un aumento del empleo a tiempo parcial, en el que compaginan la pesca con otras actividades. Anteriormente se compaginaba la pesca con el cultivo del arroz, pues la pesca era una actividad que se practicaba de octubre a marzo, mientras que el mayor laboreo en los arrozales se producía de mayo a octubre, con lo cual ambas eran complementarias.

El proceso de terciarización no ha provocado la desaparición de la pesca y la agricultura, las dos actividades tradicionales, sino que lo que ha supuesto es la disminución de la población activa que se dedica a estas dos actividades, es decir, "las transformaciones de los sectores secundarios y terciarios han influido a las comunidades 
pesqueras" (Viruela, 1995, p. 2). La mayoría de la población activa tiene su lugar de empleo en los restaurantes. Hoy en día, los que todavía pescan, lo hacen generalmente como actividad complementaria, debido a que los beneficios que se obtienen no son suficientes para subsistir. Debido a la proliferación de estos establecimientos en el pueblo, surgió la Asociación de Hostelería del Palmar. Ha tenido iniciativas para potenciar este sector, como por ejemplo el "Concurs d'all i pebre" que empezó en el año 2010, en el cual participan los restaurantes locales, y se visualiza por las calles del pueblo, en que junto a las mesas exteriores no sólo se encuentran los carteles con los precios sino también un estandarte en el cual indica el lugar en el que ha quedado calificado en dicho concurso en ese año, y que puede servirle al visitante para saber en qué restaurante supuestamente su cocina es de mayor calidad.

La pesca y el cultivo del arroz han vertebrado la vida tanto económica como social del Palmar. Hoy éstos han quedado como un patrimonio inmaterial, pues la primera actividad es la raíz que originó este asentamiento, girando sus costumbres y modos de vida tradicionales alrededor de ella, para más tarde pasar a complementarse con la segunda tras las colonizaciones. Quien articula hoy económicamente esta pedanía es la hostelería, con sus numerosos restaurantes. Los turistas vienen atraídos por la calidad y fama de sus platos típicos. Pero junto a esto, creemos no se debería olvidar a quien ha sido el sustento de la población durante su historia, la pesca y agricultura y que son la materia prima de la actividad que mueve hoy a este núcleo rural, es decir de la gastronomía, pues esta se basa en los productos sacados del lago como las anguilas y la lisas, y el arroz local, y para ello se debería apoyar a la agricultura familiar, por ejemplo pagando unos precios adecuados por los producto a los pescadores y agricultores.

El capitalismo ha propiciado la transformación de este medio rural, tan aislado del exterior hasta la penetración de este sistema, pasando de ser un espacio para la obtención de recursos a un bien de consumo, para los turistas. Se ha producido una dicotomía entre el medio rural y el medio urbano, que se manifiesta con la creación de infraestructuras para el turismo, como son por ejemplo los embarcaderos, que se han creado para los visitantes que llegan a través de las rutas guiadas. Esto también ha tenido otro efecto, la invasión de los automóviles y autobuses.

En cuanto a los medios de transporte con la introducción del capitalismo en esta comunidad rural, se han ido produciendo cambios significativos. En el pasado el medio de transporte para entrar y salir de El Palmar era los barquets. Hoy día la posibilidad de viajar como los antiguos habitantes de la Albufera se ha convertido en un negocio lucrativo. Ahora las barcas que circulan por las aguas del lago son motorizadas. Actualmente encontramos vehículos privados en todo el pueblo (coches). También destaca la presencia por las calles de vehículos que expresan el carácter rural de este espacio, como tractores, pues son vehículos muy difíciles de ver circulando por un viario de un espacio urbano, es algo inimaginable. Debido al carácter de masas del turismo, tanto del turismo que viene en busca de la gastronomía, como de aquel que viene de visita guiada entre semana como turismo natural, es decir tanto los que vienen con automóvil privado como en autobús, se ha habilitado de una gran zona de aparcamiento a la entrada del pueblo, frente a los embarcaderos, para que no desvirtúen el paisaje interior del pueblo, pues la circulación de todos estos vehículos por el callejeros provocaría una alteración negativa para los intereses locales, tanto visual como económicamente. 
Ha habido una evolución muy superior en el cultivo de arroz en el último medio siglo que en el resto del tiempo pasado desde la introducción del arroz. Se ha producido un aumento de la productividad por horas de trabajo, lo que ha hecho incrementar de forma considerable los rendimientos agrícolas. Es decir se ha incrementado la productividad reduciendo a su vez las horas de trabajo. Como efecto negativo la introducción de la maquinaria ha hecho que la mano de obra que se necesita para esta actividad haya disminuido en este periodo.

Para el método de cultivo que se emplea, la siembra al voleo, la maquinaria que se utiliza son las sembradoras y las cosechadoras. La implantación de la mecanización ha supuesto también la utilización de lubricantes y engrases. Los lubricantes se obtienen a través de la refinación del crudo. Los engrases están formados de una mezcla semisólida de petróleo y de jabón. Conforme se ha ido haciendo más sofisticada la maquinaria introducida, debido a la complejidad cada vez mayor de piezas que presentan, se ha ido haciendo mayor y más compleja la necesidad de grasas, y de una mejor calidad. La maquinaria se utiliza para diversas acciones como son preparar la tierra para la plantá, arrancar las malas hierbas, o mejorar las condiciones del terreno. Las sembradoras se encargan de introducir las semillas en el suelo buscando la forma más óptima posible de realizar esta acción, para lograr una buena germinación. Aquí encontramos uno de los cambios que se han producido, pues hasta que se introdujo la mecanización se hacía a voleo.

\section{DIVERSIDAD DE LA ECONOMÍA, ENTORNO NATURAL E IDENTIDAD LOCAL}

Se podría mejorar la situación de esta pedanía, evitando el desarrollo rural, y apostando por el desarrollo agrario con especial atención de no castigar al entorno natural ni cultural. Seguramente nos habremos dejado alguna buena medida para conseguir para conseguir mejorar la situación en El Palmar, y también creemos que no todos los lectores compartirán nuestras opiniones.

Se deberían tomar medidas para sustituir la homogenización actual por la que se apostado, pues depender prácticamente del turismo rural y de la hostelería puede resultar peligroso. En nuestra opinión, entre las medidas que se prevén necesarias, la más clara sería la revitalización de las actividades tradicionales. Para ello creemos que es necesario rejuvenecer la pesca, pues la mayoría de los pescadores que se dedican exclusivamente a esta actividad, debido a los bajos ingresos que proporciona, son personas jubiladas. Los ingresos de los pescadores son cada vez menores, porque los gastos son mayores mientras que el precio de sus capturas cada vez más bajos. Se debería proteger esto, para que la gente joven vuelva a sentirse atraída por esta actividad, en la cual hasta hace muy poco se luchaba por realizar, y hoy en día es una actividad marginal.

En cuanto a las oportunidades que se encuentran para promover el desarrollo local sin dañar el entorno, se puede destacar la posibilidad de recuperar un oficio ya perdido, que cuando se realizaba no se consideraba como tal, sino como una actividad complementaria y que era realizado por las mujeres, es decir, la reparación de redes. Hoy en día no se trataría de reparar redes, sino de fabricarlas a modo de artesanía local, 
pues es un elemento de la historia local, y puede que entre los visitantes tuviese éxito y se consiguiesen obtener ingresos. Una tienda de recuerdos relacionada con objetos de las actividades tradicionales o de las costumbres locales, crearía una atmósfera ideal para atrapar al turista.

Parece muy acertada la decisión que se tomó de unirse los agricultores con la creación de la cooperativa S.A.T. $n^{\circ}$ 990, la cual ha creado una marca propia. Potenciar esta marca de arroz local "La Espiga del Palmar" sería un gran acierto, aunque también es cierto que esta medida ya está en marcha pues poco a poco se está empezando a abrir el arroz local al exterior. Esta se compone de las variedades Sendra y Albufera, pues están consideradas de muy buena calidad y que muy bien ha sabido aprovechar la hostelería local para ser la principal fuente de ingresos del pueblo. Pero con una buena política de marketing, como sí que se ha hecho en el tema de la gastronomía local o el turismo natural, se podría proyectar más allá y conseguir una mejor comercialización de este producto, basándose en su calidad.

Se observan algunas carencias en cuanto a dotaciones. Se pueden destacar dos: un servicio de transporte público insuficiente y la falta de instalaciones para la práctica de deportes. Sí que existen en el pueblo otros servicios que para el número de habitantes se pueden considerar adecuados, como son el colegio ubicado a la entrada del pueblo o el centro médico. En cuanto al transporte público, el hecho de que sólo exista una línea entre El Palmar-Valencia, dificulta y condiciona mucho la movilidad de la población de personas, sobre todo para algunos sectores de población, como la población vieja, que debido al factor envejecimiento es importante en número, o a la población sin carnet de conducir o sin automóvil privado. Y la falta de instalaciones deportivas también limita a aquella población que desee practicar un deporte, sobre todo los jóvenes, y se han de desplazar a otros lugares para practicar su deporte, pues las dotaciones que hay son nimias. Pensamos que se podrían mejorar estos dos aspectos, pues son dotaciones que se encuentran en situación deficitaria y, sin embargo, sí que se aprecia que se ha invertido en otra clase de equipos e infraestructuras relacionados con el turismo.

También parece que existe un exceso de carteles publicitarios, que se encuentran por todo el pueblo, en postes junto a los canales que rodean el pueblo, en fachadas, en vallas, etc. Esta abundancia de carteles publicitarios y pintadas no es algo que dañe el entorno natural, pero sí el visual, pues contribuyen a desvirtuar el carácter tradicional de este espacio, pues muestran la conquista de un paisaje rural por la publicidad y las estrategias del capital.

En cuanto al tipo de vivienda, un elemento clave para la conservar el carácter pintoresco y rural de este pueblo pese a la monopolización paisajista de restaurantes actual, sería seguir con el tipo de viviendas actual de una planta de altura, algunas con solo planta baja, pues no encontramos edificaciones verticales en todo el núcleo, y que su intrusión desfiguraría este carácter pintoresco.

Por último, sería oportuno hacer alusión a un aspecto negativo que debería desaparecer, aunque esto modificaría en parte la identidad local. Se trata de la discriminación de la mujer en la participación en algunas actividades, que por tradición ha tenido vedadas, y sólo ha podido entrar actualmente a través de los Tribunales. El peso de la tradición y la historia ha condicionado que la Comunidad haya pervivido anclada en el pasado. 


\section{ACTIVIDADES ECONÓMICAS Y CONSERVACIÓN DEL MEDIO NATURAL: ¿COMPATIBILIDAD O INCOMPATIBILIDAD?}

El nivel de contaminación de la Albufera alcanzó límites elevadísimos en las últimas décadas del siglo XX debido a la mezcla de los residuos que tenían tres orígenes: urbanos, industriales y agrícolas. Vamos a hablar un poco sobre estos, para luego ver cuáles serían en nuestra opinión las posibilidades que se pueden seguir sin dañar la Albufera.

\section{Contaminación por la generalización del binomio productos químicos e industrialización-urbanización, y la aparición de nuevas estrategias del capital}

La introducción del capitalismo supuso también la introducción de la revolución verde en la década de los años sesenta del siglo XX. Ésta trajo consigo la utilización de forma masiva de los fertilizantes y productos químicos como pesticidas o plaguicidas, que junto a la mecanización comentada anteriormente tuvieron una gran influencia en el aspecto socio-económico con el aumento de la productividad pero con la reducción de la mano de obra en las labores del cultivo del arroz. Todas estas innovaciones contribuyeron a la intensificación de la agricultura con la que se aumentaban los rendimientos en la producción, pero como efecto opuesto se aumentaba la contaminación de la Albufera, hasta llegar a elevadas cotas de contaminación como consecuencia de estos productos utilizados en la agricultura. Pero también en esta década se produce el despegue de la industria y la urbanización, que tienen como efecto el aumento de los vertidos de las urbanizaciones e industrias que llegaban al lago. Todo ello provocó que el lago se convirtiese en una cloaca, y como consecuencia de estos procesos la muerte de muchísimos peces.

Sí que es compatible la conservación de la Albufera con las actividades tradicionales, es decir con la agricultura y la pesca, siempre y cuando en el ciclo del arroz se haga de una forma limpia. Para conservar y proteger este espacio, declarado Parque Natural en 1986, no se debería apartar ni marginar a las actividades agropecuarias, ya que estas también forman parte de este espacio protegido y la mejor manera de conservarlo es a través de la convivencia de ambas, pues no estamos a favor de los principios conservacionistas en los cuales el ser humano no tiene lugar en espacios protegidos, en los cuales ha vivido durante toda su historia en perfecto equilibrio con la naturaleza. También pueden existir opiniones que argumenten que los arrozales son un medio antrópico, y tienen toda la razón del mundo, pues hasta hace poco más de un siglo no existían, y que por tanto estos también afectan al medio natural. Pero se puede argumentar a favor de esta opinión, qué estos campos de arroz son el refugio de muchas aves que visitan la Albufera.

Por el contrario, el turismo masificado que se ha implantado en las últimas décadas, no es muy positivo para este medio natural. Por ejemplo en esas visitas que se han generalizado con la idea de "paseo en barca", se puede perturbar al ecosistema, debido a que esta clase de turismo ha adquirido un carácter de masas, pues todos los días son numerosas las visitas que se reciben, desde su implantación por el modelo capitalista. Esto puede tener repercusiones principalmente en la fauna. 
La utilización de pesticidas puede generar beneficios, ya que estos tienen el objetivo de combatir las plagas que dañan el cultivo. Pero su utilización masiva hace que sus inconvenientes puedan ser mayores que sus beneficios, debido a los daños que pueden causar al medio natural. Este tipo de productos, al mezclarse con otros componentes como el agua, que encontramos de forma permanente en el lago, tiene una interacción química que puede formar como resultado un producto más dañino que el original. Los pesticidas pueden dañar no solo a la flora y la fauna, sino también al ser humano que consume los peces capturados como resultado de la actividad pesquera realizada en este espacio, pues estos productos se pueden introducir en la cadena alimentaria de la fauna.

Una de las consecuencias de la introducción de productos químicos para el campo, como los herbicidas o plaguicidas, ha sido que han propiciado la desaparición de elementos tradicionales del lugar, como un plato típico como la ratà, que consistía en el guiso en el cual su ingrediente clave era la rata de marjal, que se capturaban principalmente durante los periodos de inundación de los campos de arroz, pues este era el medio donde vivían, alimentándose de él, y que al llenarse de agua se veían obligadas a huir. Puesto que se alimentaban del arroz, su contaminación por la utilización de los productos químicos, hizo que se empezara a abandonar este plato.

Los pesticidas se pueden clasificar en varias clases, según qué finalidad tengan. Pueden ser herbicidas, insecticidas o fungicidas (para combatir los hongos). Según E. Primauro (1990, p. 32), "la mayor parte de estos compuestos presenta propiedades hidrofóbicas, lo cual hace que sean poco solubles en el agua". Esto puede hacer que los daños causados sean mayores. Los pesticidas pueden causar daños a la fauna avícola que se encuentra presente en este medio natural, pues esta se puede nutrir de alimentos que contengan estos productos. También pueden sufrir cambios en los ritmos biológicos. Estos productos químicos debido a la baja solubilidad anteriormente comentada, se puede quedar en el agua, y debido al estancamiento del agua y su baja movilidad en este medio albufereño se pueden quedar concentrados. De esta manera se puede introducir en la cadena alimenticia de la fauna acuática presente en el lago, y a través de esta pasa a los seres humanos. Por tanto pueden tener riesgos para salud humana si se utilizan de forma masiva. Este riesgo se puede presentar o bien tras ingerir el pescado o bien a través del aire entrado por el aparato respiratorio.

\section{La eliminación de los restos del cultivo del arroz}

El cultivo del arroz tiene restos de paja que han de quemarse tras la siega, es decir a finales de septiembre o en octubre. Esto al quemarse genera $\mathrm{CO}_{2}$. Pero el verdadero problema para el ecosistema se produce si estos residuos no se han quemado y se producen lluvias, se pudren y produce gas metano.

En los últimos años ha surgido un nuevo conflicto relacionado con los residuos de la actividad agrícola. Pero esta vez, por el contrario la lucha ha sido entre actores diferentes, ahora ha sido entre los agricultores y pescadores locales por una parte, frente a una organización supranacional, la Unión Europea, por la otra. Una de las exigencias para cobrar las ayudas comunitarias es el control de la eliminación de restos de cosechas, es decir la prohibición de la quema de rastrojos. Por tanto, la Unión Europea prohibió la quema de la paja a los agricultores de El Palmar a cambió de seguir 
prestando las ayudas económicas de 476 euros anuales por hanegada. Aunque este conflicto a simple vista afecta sólo a los agricultores que son los que reciben las ayudas del arroz, por el contrario también incumbe a los pescadores, pues la quema de la paja también les afecta indirectamente, pues como se ha dicho anteriormente, si la paja no se quema, provoca daños que pueden ser mayores que los que supuestamente puedan causar al medio ambiente, ya que si se producen lluvias esta paja se pudre, provoca una enorme contaminación por emisión de metano que al introducirse en el lago reduce el oxígeno del agua, con la consecuente muerte de muchos peces. De ahí que en el 2012 la Comunidad de Pescadores solicitase una moratoria para buscar una posible solución, que fue desestimada por la UE.

Una posible solución consiste en buscar una alternativa con la paja, como podría ser su recogida para su utilización para otras actividades, de manera que con esta medida se podría prevenir la contaminación y a su vez generar actividad económica. Entre estas alternativas aparece la obtención de energía, pero esta "tiene el inconveniente de generar escasos beneficios y apenas cubrirá los costos de retirar la paja” (Navarro, 2006, p. 1). Al no ser rentable a ninguna empresa privada, debería aparecer el papel de las ayudas económicas.

Como contrapartida a este problema, han surgido proyectos como el AFTEC, para evitar la contaminación ambiental que genera la quema de estos residuos. Este proyecto pretende que esta paja sea reciclada en papel, y eso a su vez puede generar una revitalización del cultivo del arroz, pues con la quema de la paja se está desaprovechando un posible recurso económico auxiliar para los agricultores, que podría generar empleos, todo esto desde la perspectiva económica. Además desde la perspectiva medioambiental se evitaría contaminar la atmósfera, y mientras que si no se ha quemado la paja y llueve los daños por el metano generado son todavía mayores, y además al no quemarse se propagan las malas hierbas con lo que se generan plagas, y esto hace que se haya de utilizar una mayor cantidad de productos químicos para combatirlas.

Por todo esto, parece una buena opción, pero para ello es necesario que haya subvenciones, pues estas medidas pueden contribuir al desarrollo sostenible del medio rural al "crear una nueva fuente de ingresos para los agricultores en las actividades de recogida y logística de la paja" (Navarro, 2006, p. 2), de esta forma los agricultores no saldrían perdiendo pues conseguirían unos ingresos adicionales por la paja generada en sus parcelas, de la manera que a su vez desaparecería un conflicto ha alterado tanto a los agricultores como a los pescadores del lugar en los últimos años

\section{CONCLUSIÓN}

Como conclusión, se observa que existe una falta de conocimiento sobre el lugar y sus costumbres, pues para realizar este estudio apenas se ha encontrado bibliografía e información, pese a ser un lugar tan singular con un entorno tan bello y unas tradiciones tan arraigadas que se han mantenido vírgenes hasta hace unas décadas, y lo poco que conoce la gente es a través de la novela "Cañas y barro", de Vicente Blasco Ibáñez. Para ello el Ayuntamiento (el de la pedanía), pero también el Ayuntamiento de Valencia, pues no hay que olvidar que administrativamente pertenece a esta, podrían dar a conocer 
más sobre la historia y tradiciones autóctonas con la creación de algún libro o una página web, pues aunque sí que existen páginas web en las que se habla brevemente sobre las costumbres locales como por ejemplo en la páginas web de algún restaurante, pero estas tienen tintes publicitarios y no profundizan sobre la vida o la historia del lugar siendo muy superficial la información que proporcionan, o la página web de albufera.com que también aparece en algunos carteles por el pueblo, que también tiene los mismos tintes publicitarios que las otras, así pues se debería hacer una mejor que las que existen, que apenas aporta nada. Debido a esto, entre otros motivos, la mayoría de los turistas que vienen, principalmente los del turismo de entre semana comentado anteriormente, no saben nada del lugar, debido a esa falta de información, mientras que los que vienen en fin de semana muchos de ellos también desconocen muchos aspectos de El Palmar, pues suelen venir solamente para degustar un plato típico, es decir vienen, comen y se van, pero prácticamente sin saber la historia del lugar y los modos de vida y costumbres tradicionales de sus pobladores, que se han tenido que abrirse al exterior debido a la crisis de los sectores tradicionales en las últimas décadas. También se podría mejorar el tema de las comunicaciones, mejorando el transporte público, pues existe una línea de autobuses que enlaza la pedanía con Valencia, pero parece ser que es deficitaria, y que se podrían crear otras líneas con otros municipios cercanos, puesto que esta escasez de medios de transportes públicos limita las comunicaciones al automóvil privado, y eso puede crear dependencia en algunas personas de cierta edad que no tengan automóvil y esto dificulta su movilidad.

Anteriormente se ha comentado que desde el exterior se conoce poco de la historia y de la vida en El Palmar, y que prácticamente todo la información que se tiene es a través de publicidad para el turismo, pero a esto hay que sumarle un aspecto negativo, pues en los últimos años El Palmar se ha dado a conocer por su salida en los medios de comunicación debido a los conflictos por la entrada de la mujer en la Comunidad de Pescadores, la división interna que se generó. Sobre este conflicto sí que existe numerosa bibliografía. Por tanto el papel de la mujer en la actividad económica, relacionada con el anquilosamiento de la Comunidad de Pescadores ha sido uno de los temas tratados más importantes de este lugar. Para que haya podido ser miembro de esta, y realizar la actividad que por herencia le correspondía, se ha tenido que recurrir a los tribunales, es decir que si no hubiese sido por esta vía, hubiese seguido esta marginación. Se tendría que haber evitado llegar a este punto, pues la Comunidad de Pescadores se tendría que haber adaptado a los tiempos presentes en este aspecto.

Otro de los temas tratados en este estudio, aunque sin profundizar excesivamente, y del cual se han generado numerosos conflictos en las últimas décadas, ha sido el de la relación de las actividades económicas tradicionales y la contaminación que estas han generado o generan en el medio natural de la Albufera. En los últimos años se ha tenido que recurrir a los Tribunales por el tema de la eliminación de la paja del arroz. Esta resulta un problema, y para ello debe de encontrarse una solución, que permita mantener las ayudas europeas que recibe el arroz, un sector tan dependiente de estas, pero logrando con esta solución evitar la contaminación, ni perjudicar a la otra actividad económica tradicional, la pesca. Y si esta "solución" permite ingresos auxiliares y generar empleos podría contribuir a revitalizar el sector agrícola.

Para finalizar, se podría decir que la identidad local no se ha perdido totalmente, pues se ha conseguido mantener una institución que perdura desde época medieval, como es la Comunidad de Pescadores, pero esta ha quedado como algo a modo de patrimonio. 
Debería modernizarse dicha comunidad en algunos aspectos, pues carece de estatuto y solamente se rige por las normas de carácter consuetudinario. Tradicionalmente ser vecino de El Palmar significaba ser pescador, hoy en día no ocurre lo mismo, pues un habitante local podría decir con mayor probabilidad "soy de El Palmar y trabajo en un restaurante".

\section{BIBLIOGRAFÍA}

BLASCO IBÁÑNZ, V:. Cañas y barro. Barcelona: Bibliotex, 2001.

BURRIEL, E. L. La Huerta de Valencia. Zona Sur. Estudio de Geografía Agraria. Valencia: Alfonso el Magnánimo, 1971.

CARUANA, L. Estudio histórico y jurídico de la Albufera de Valencia. 1954.

FERNÁNDEZ, F. El ingreso en la comunidad de pescadores de El Palmar y la transmisión hereditaria del "redoli". Valencia: Universidad de Valencia, 2001.

GARCÍA, E. Arroz, cultivo y comercio. Madrid: Espasa-Calpe, 1929.

GOBERNA, A. Contaminación en la Albufera: análisis de sus aguas. Valencia: Centro Francisco Tomás y Valiente, 2002.

L'ESCRIVÀ, J: Les nostres barraques. Mislata, 1976.

MICHAVILA, A: La barraca valenciana. Madrid: Real Sociedad Geográfica, 1918.

NAVARRO, E. El problema de la paja en el Parque Natural de la Albufera de Valencia y su solución como sumidero de $\mathrm{CO}_{2}$, en el proyecto AFTEC. Valencia: Universidad de Valencia, 2006.

PRIMAURO, E. Los pesticidas y el medio ambiente. Valencia: Universidad de Valencia, 1990.

ROSSELlÓ, V. M. L'Albufera de Valencia. Barcelona: Publicacions de l'Abadia de Montserrat, 1995.

SANCHÍS, C. Regadiu i canvi ambiental a l'Albufera de Valencia. Valencia: Universidad de Valencia, 2001.

SANMARTín, R. La Comunidad de Pescadores de El Palmar. Su estudio jurídico y antropológico. Valencia, 1976

SANMARTÍN, R. La Albufera y sus hombres. Madrid: Akal, 1982.

SMITH, H. y WILKES, L. Maquinaria y equipo agrícola. Barcelona: Omega, 1979. 
TORRO, J. Poblament i espai rural: transformacions històriques. Valencia: Alfonso el Magnánimo, 1990.

VIRGILI, P. Aprovechamiento piscícola de l'Albufera y marjales lindantes. Valencia: Ayuntamiento, 1956.

VIRUELA, R. Las comunidades pesqueras ante la crisis de las pesquerías y el cambio económico. Cuadernos de Geografía, 1995, nº 57, p. 153-182.

ZARAGOZA, M. El cultiu tradicional de l'arròs a Silla (L'Albufera de Valencia). Valencia: Universitat de València, 1982.

\section{RECURSOS ELECTRÓNICOS}

Oficina de Estadística del Ayuntamiento de Valencia. Disponible en: $<$ http://www.valencia.es/estadística $>$. [Consultado: mayo de 2013].

(C) Copyright Antonio Bellón Climent, 2014.

(C) Copyright GeoGraphos, 2014.

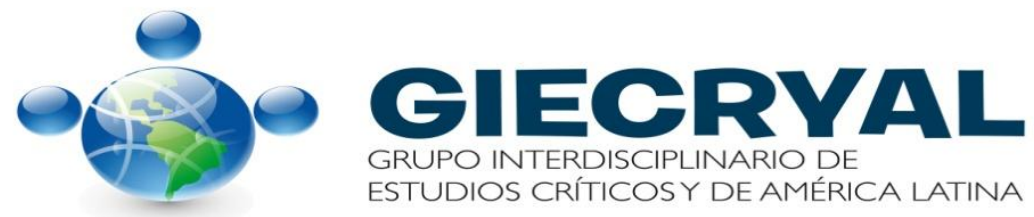

